УДК 630*160:582.475.4

\title{
ИЗУЧЕНИЕ ТЕРПЕНОВОЙ ФРАКЦИИ ЭФИРНОГО МАСЛА ХВОИ СОСНЫ ОБЫКНОВЕННОЙ (PINUS SYLVESTRIS L.), ПРОИЗРАСТАЮЩЕЙ В УСЛОВИЯХ ПОРОДНОГО ОТВАЛА КЕДРОВСКОГО УГОЛЬНОГО РАЗРЕЗА
}

\author{
(C) О.А. Неверова ${ }^{1}$, О.Л. Цандекова ${ }^{2 *}$ \\ ${ }^{1}$ Кемеровский государственный университет, ул. Красная, 6, Кемерово, \\ 650043 (Россия), e-mail: nev11@yandex.ru \\ ${ }^{2}$ Институт экологии человека Федерального исследовательского центра \\ угля и углехимии СО РАН, пр. Ленинградский, 10, Кемерово, 650065 (Россия), \\ e-mail: zandekova@bk.ru
}

Методом хромато-масс-спектрометрии изучен качественный и количественный состав терпеновой фракции эфирных масел, полученной из хвои Pinus sylvestris L., произрастающей в условиях породного отвала Кедровского угольного разреза Кузбасса. Результаты исследований регистрировались на приборах Agilent 5973N и Agilent 5973N EI/PCI. Разделение компонентов эфирных масел проводили на газовых хроматографах серии Agilent 6890, входящих в состав хромато-масс-спектрометрических систем. Масс-спектры регистрировались на квадрупольном массспектрометре HP MSD 5971 при ионизации электронным ударом с энергией ионизирующих электронов 70 эВ. В ходе исследований идентифицировано 37 компонентов терпеновой фракции эфирных масел, из них 14 - монотерпены и 23 сесквитерпены. Выявлено влияние эдафических условий эмбриоземов отвала и возраста деревьев на состав терпенов хвои $P$. sylvestris. Дефицит в эмбриоземах нитратного азота и подвижного фосфора способствовал увеличению общего содержания терпенов у деревьев разного возраста. Установлено повышение количества терпенов у растений второго класса возраста в сравнении с более молодыми деревьями. Результаты проведенных исследований дают основание рассматривать насаждения сосны обыкновенной на отвалах угольных разрезов Кузбасса как ресурсную базу для получения эфирных масел.

Ключевые слова: Pinus sylvestris L., эфирные масла, терпены, монотерпены, сесквитерпены, отвалы угольных разрезов.

\section{Введение}

В Кузбассе сосредоточено около 5 тыс. промышленных предприятий, в том числе более 50 шахт и угольных разрезов. В результате угледобычи площадь нарушенных земель в Кузбассе превышает 100 тыс. га. Экологические условия формирующихся на отвалах эмбриоземов существенно отличаются от зональных в сторону олиготрофности и ксероморфизма, поэтому число видов растений, способных успешно произрастать здесь, в значительной степени ограничено. Экспериментально установлено, что одним из пригодных видов для произрастания на породных отвалах является сосна обыкновенная (Pinus sylvestris L.) $[1,2]$. Она является ценным лекарственным растением, обладает разносторонней биологической активностью. Особый интерес у исследователей вызывает изучение состава летучих соединений сосны обыкновенной, который по количественному содержанию и качественному составу терпеновых фракций много-

Неверова Ольга Александровна - доктор биологических наук, профессор кафедры экологии, e-mail:nev11@yandex.ru

Цандекова Оксана Леонидовна - кандидат сельскохозяйственных наук, научный сотрудник, e-mail: zandekova@bk.ru кратно превосходит другие виды растений [3]. Терпены и терпеноиды широко используются в производстве ядохимикатов. В медицине их применяют в качестве дезинфицирующих средств, а также в производстве ароматов [4-6]. В связи с вышеска-

\footnotetext{
* Автор, с которым следует вести переписку.
} 
занным отвалы угольных разрезов могут рассматриваться в качестве дополнительной сырьевой базы для интродукции P. sylvestris с целью получения эфирных масел.

Цель работы - изучить качественный и количественный состав терпеновой фракции эфирных масел хвои разновозрастных деревьев P. sylvestris, произрастающих в различных эдафических условиях породного отвала угольного разреза «Кедровский».

\section{Экспериментальная часть}

Объектом исследований служили деревья P. sylvestris первого (10-15 лет) и второго (20-25 лет) класса возраста, произрастающие на исследуемых площадках наблюдений (ПН) отвала. Растительные образцы собраны в конце летнего периода, эфирные масла выделяли из хвои двухлетнего возраста. Эксперимент проведен в 2012-2013 гг. на двух ПН: № 1 - спланированный отвал с нанесением потенциально плодородного слоя (ППС), № 2 - спланированный отвал без нанесения ППС. Отвал «Южный» угольного разреза «Кедровский» имеет равнинно-наклонный рельеф с высотой 58 м, площадь составляет 599,3 га. Возраст отвала 30-35 лет. Породы отвала представлены песчаником (60\%), алевролитами (20\%), аргиллитами $(15 \%)$, суглинками и глинами (5\%). Преобладающей фракцией являются крупные агрегаты (от 3 до 10 и более мм), содержание мелких частиц снижено.

По агрохимическим показателям эмбриоземы ПН характеризуются высокой обеспеченностью обменным калием (100-240 мг/кг) и низкой обеспеченностью подвижным фосфором (10-50 мг/кг). На ПН № 1 отмечается средняя обеспеченность нитратным азотом (9,5-13,8 мг/кг). Эмбриоземы ПН № 2 в сравнении с ПН № 1 характеризуются низкими значениями обменного фосфора и нитратного азота (10-20 и 3,6-6,0 мг/кг соответственно) и, следовательно, имеют менее благоприятные эдафические условия для произрастания растений [7]. Гигиеническая оценка эмбриоземов отвалов показала, что содержание искусственных радионуклидов (Sr-90 и Cs-137) существенно ниже среднего регионального уровня, содержание естественных радионуклидов находится в пределах фоновых величин радиоактивных элементов в земной коре. Содержание тяжелых металлов в эмбриоземах отвалов не превышает ПДК, принятых в Российской Федерации [8-10].

Подготовку сырья (высушивание до воздушно-сухого состояния) и получение эфирного масла гидродистилляцией (отгонкой с паром) проводили с использованием общепринятых методов [11]. Анализируемую смесь (1-10 мкл) растворяли в 500 мкл ацетона и к полученному раствору добавляли 100 мкл гексанового раствора смеси, содержащей равные весовые количества нормальных углеводородов С8, С9, ..., С24 суммарной концентрации $0,1 \%$.

Хромато-масс-спектрограммы регистрировались на приборах Agilent 5973N и Agilent 5973N EI/PCI. Разделение компонентов исследуемых эфирных масел проводили на газовых хроматографах серии Agilent 6890, входящих в состав упомянутых хромато-масс-спектрометрических систем. Разделение осуществляли на кварцевой капиллярной колонке HР-5ms длиной 30 м и внутренним диаметром 0,25 мм, неподвижная фаза - сополимер 5\%-дифенил-95\%-диметилсилоксан, толщина пленки неподвижной фазы 0,25 мкм. Температура испарителя $-280^{\circ} \mathrm{C}$, объем пробы - 1 мкл, разделение потока $100: 1$. Температурный режим колонки: $50{ }^{\circ} \mathrm{C}(2$ мин $)-50-240{ }^{\circ} \mathrm{C}\left(4^{\circ} \mathrm{C} /\right.$ мин $)-240-280{ }^{\circ} \mathrm{C}\left(20^{\circ} \mathrm{C} /\right.$ мин $)-280{ }^{\circ} \mathrm{C}(5$ мин $)$. Газ-носитель - гелий с постоянным потоком 1 мл/мин. Температура интерфейса между хроматографом и масс-селективным детектором - $280^{\circ} \mathrm{C}$. Масс-спектры регистрировались на квадрупольном масс-спектрометре HP MSD 5971 при ионизации электронным ударом с энергией ионизирующих электронов 70 эВ. Данные собирались со скоростью 1,9 скан./с в диапазоне 30-650 а.е.м. (Agilent 5973N) или 3 скан./с в диапазоне области 29-500 a.e.м. (Agilent 5973N EI/PCI). Задержка между вводом пробы в испаритель хроматографа и началом записи хромато-масс-спектрограммы составляла 3,0 мин.

Компоненты исследуемых смесей идентифицировали по полным масс-спектрам, значениям линейных индексов удерживания, приведенным в руководстве [11].

\section{Результаты и обсуждение}

Анализ результатов хромато-масс-спектрометрического исследования показал, что в составе эфирных масел хвои P. sylvestris идентифицировано 37 компонентов терпеновой фракции, из них 14 - это монотерпены и 23 - сесквитерпены. Доминирование сесквитерпенов в терпеновой фракции эфирных масел сосны, наблюдаемое в нашем исследовании, согласуется с работами ряда ученых [12-16]. На разных пло-

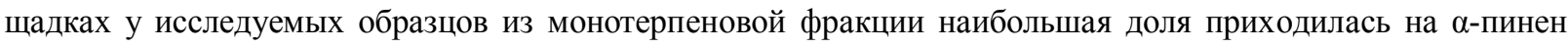


$(11,18-18,13 \%)$ и 3-карен $(6,14-7,24 \%)$. Сходные результаты публикуют и другие ученые [17-19]. Среди сесквитерпенов в количественном отношении в хвое исследуемых деревьев преобладали $\delta$-кадинен+транскаламенен (5,31-15,23\%), $\gamma$-кадинен (5,10-8,82\%), 4-эпи-кубебол+бициклогермакрен $(2,37-5,71 \%)$, гермакрен D (1,06-5,42\%), $\alpha$-муролен (2,07-2,39\%), остальные компоненты этого класса встречались в небольших количествах.

Сравнительная характеристика состава терпенов хвои сосны в зависимости от эдафических условий показала, что на ПН № 2 (площадка с низким содержанием в эмбриоземах нитратного азота и обменного фосфора) общее количество терпенов, а также массовая доля сесквитерпенов превалировала у исследуемых растений первого и второго класса возраста в сравнении с ПН № 1. Так, на ПН № 2 общее количество терпенов находилось в пределах от 72,61 до 74,68\%, на ПН № 1 - от 59,38 до 65,58\%; количество сесквитерпенов - 41,55-48,09\% и 31,29-37,4 \% соответственно (табл.).

Хромато-масс-спектрометрическое исследование терпеновой фракции эфирного масла хвои P. sylvestris

\begin{tabular}{|c|c|c|c|c|}
\hline \multirow{4}{*}{ Наименование компонента } & \multicolumn{4}{|c|}{ Площадки наблюдений (ПН), возраст сосны } \\
\hline & \multicolumn{2}{|c|}{ ПН № 1} & \multicolumn{2}{|c|}{ ПН № 2} \\
\hline & $10-15$ лет & 20-25 лет & 10-15 лет & $20-25$ лет \\
\hline & \multicolumn{4}{|c|}{ Содержание компонента (количество в пробе, \%) } \\
\hline \multicolumn{5}{|c|}{ Монотерпеньи } \\
\hline$\beta$-мирцен & 0,76 & 0,68 & 0,94 & 0,58 \\
\hline транс- $\beta$-оцимен & 0,35 & - & 0,35 & 0,53 \\
\hline лимонен+ $\beta$-фелландрен & 0,66 & 0,50 & 0,55 & 0,44 \\
\hline терпинолен & 0,80 & - & 0,77 & 0,81 \\
\hline$\alpha$-терпинен & 0,05 & + & 0,05 & 0,06 \\
\hline$\gamma$-терпинен & 0,11 & - & 0,11 & 0,11 \\
\hline$\alpha$-пинен & 15,45 & 15,11 & 18,13 & 11,18 \\
\hline$\beta$-пинен & 0,95 & 1,19 & 1,55 & 1,72 \\
\hline камфен & 2,13 & 2,22 & 3,35 & 1,42 \\
\hline сабинен & 0,19 & 0,21 & 0,20 & 0,14 \\
\hline 3-карен & 6,14 & 7,24 & 6,33 & 7,11 \\
\hline трициклен & 0,47 & 0,53 & 0,64 & 0,31 \\
\hline пара-цимол & 0,05 & 0,31 & 0,07 & + \\
\hline Всего монотерпенов & 28,18 & 28,09 & 33,13 & 24,52 \\
\hline \multicolumn{5}{|c|}{ Сесквитерпены } \\
\hline кариофиллен & 2,00 & 3,01 & 1,89 & 2,61 \\
\hline гермакрен D & 4,36 & 1,06 & 5,42 & 4,22 \\
\hline гермакрен А & 1,03 & 0,39 & 0,89 & 0,83 \\
\hline гумулен & 0,35 & 0,61 & 0,34 & 0,46 \\
\hline$\beta$-элемен & 0,45 & 0,48 & 0,39 & 0,35 \\
\hline$\beta$-кубебен & 0,17 & 0,35 & 0,25 & 0,33 \\
\hline 4-эnи-кубебол+бициклогермакрен & 3,83 & 2,37 & 3,87 & 5,71 \\
\hline$\alpha$ - копаен & 0,35 & 0,72 & 0,43 & 0,67 \\
\hline$\beta$-копаен & 011 & 0,23 & 0,18 & 0,21 \\
\hline$\alpha$-муролен & 2,07 & 2,39 & 2,34 & 2,26 \\
\hline$\gamma$-муролен & 0,99 & 1,79 & 1,36 & 1,59 \\
\hline транс-кадина-1(6),4-диен & 0,41 & - & 0,41 & 0,46 \\
\hline транс-кадина-1,4-диен & 0,39 & + & 0,37 & 0,52 \\
\hline транс-мурола-3,5-диен & 0,18 & - & 0,17 & 0,25 \\
\hline uңис-мурола-3,5-диен & 0,10 & - & 0,06 & 0,13 \\
\hline ичис-мурола-4(14),5-диен & 0,28 & 0,24 & 0,34 & 0,43 \\
\hline бициклосесквифелландрен & 0,44 & 0,29 & 0,51 & 0,61 \\
\hline$\gamma$-кадинен & 5,10 & 8,82 & 5,98 & 8,27 \\
\hline$\alpha$-кадинен & 0,47 & 0,48 & 0,51 & 0,52 \\
\hline$\delta$-кадинен+транс-каламенен & 13,15 & 5,31 & 14,16 & 15,23 \\
\hline$\beta$-бурбонен & 0,15 & 0,25 & 0,30 & 0,19 \\
\hline аромадендрен & 0,15 & 0,59 & 0,27 & 0,53 \\
\hline$\beta$-селинен & 0,87 & 1,91 & 1,11 & 1,71 \\
\hline Всего сесквитерпенов & 37,4 & 31,29 & 41,55 & 48,09 \\
\hline Всего терпенов & 65,58 & 59,38 & 74,68 & 72,61 \\
\hline
\end{tabular}

Примечание: символ «+» означает, что соответствующий компонент присутствует, но его содержание не превышает $0,05 \%$; «-»- соединение отсутствует. 
Установлено влияние возраста на перераспределение массовых долей компонентов в терпеновой фракции хвои сосны на исследуемых площадках. В частности на ПН № 1 у молодых деревьев отмечено более высокое содержание сесквитерпенов - 37,4\% (от общего количества идентифицированных веществ) и общего содержания терпенов - 65,58\%, чем у деревьев второго класса возраста (31,29 и 59,68\% соответственно). На ПН № 2 у деревьев второго класса возраста выявлено более высокое содержание сесквитерпенов $(48,09 \%)$ по сравнению с более молодыми растениями (41,55\%); содержание монотерпенов, наоборот, выше у растений первого класса возраста (33,13\%), чем у деревьев старшей возрастной группы $(33,13 \%$ и 24,52\% соответственно). Следует отметить, что неблагоприятные эдафические условия ПН № 2 способствовали увеличению качественного состава терпенов в хвое сосны второй возрастной категории.

В литературе имеются сведения о колебаниях в содержании эфирных масел в зависимости от времени года, климатических условий, отдельных экологических факторов. М.А. Пляшечник [20] установлено, что увеличение доступного азота в почве привело к перераспределению массовых долей компонентов терпеновой фракции эфирных масел Ledum palustre. И.Л. Фуксман [21] установлено увеличение содержания эфирных масел у сосны обыкновенной в условиях пониженных температур; автором отмечается, что $\alpha$-пинен быстро реагирует на стрессовые воздействия загрязнений и является оптимальными индикатором ранней диагностики состояния деревьев. Доля $\alpha$-пинена в эфирном масле монотерпеновой фракции повышалась, что связано с защитной функцией данного соединения для растения. О.В. Сотникова и Р.А. Степень [22] отмечают, что при слабой и средней степени загрязнения воздушной среды содержание эфирного масла повышалось, при сильной степени загрязнения - понижалось, при этом доля монотерпенов в эфирном масле уменьшалась.

Анализ литературных данных и результатов наших исследований позволяет предположить, что количественные перераспределения долей терпеновой фракции в хвое сосны носят неспецифический характер и возникают при любых неблагоприятных условиях, в том числе в условиях дефицита доступных форм элементов питания для растений и стрессовых воздействиях природного или антропогенного происхождения.

Синтез терпенов у P. sylvestris в условиях породного отвала также зависит от возраста деревьев, в частности у более взрослых растений (II класса возраста) в сравнении с молодыми дефицит нитратного азота и подвижного фосфора в эмбриоземах стимулирует увеличение качественного состава терпенов, что является проявлением более высокой экологической пластичности, способствующей повышению устойчивости сосны.

Результаты проведенных исследований дают основание рассматривать насаждения P. sylvestris на отвалах угольных разрезов Кузбасса как ресурсную базу для получения эфирных масел с целью их использования в фармацевтической, химической и других отраслях промышленности.

\section{Вblводы}

1. Методом хромато-масс-спектрометрии изучен качественный и количественный состав терпеновой фракции эфирных масел хвои P. sylvestris, произрастающей в условиях отвала Кедровского угольного разреза: идентифицировано 37 компонентов терпеновой фракции, из них 14 соединений монотерпенов и 23 сесквитерпенов.

2. Выявлено влияние эдафических условий отвала и возраста деревьев на состав терпенов хвои P. sylvestris: дефицит в эмбриоземах нитратного азота и подвижного фосфора способствовал увеличению общего содержания терпенов и сесквитерпенов в хвое деревьев разного возраста; у деревьев второго класса возраста в сравнении с более молодыми деревьями в неблагоприятных эдафических условиях увеличивался качественный состав терпенов. Это можно рассматривать как проявление защитных функций, способствующих повышению устойчивости сосны.

3. Насаждения сосны обыкновенной на отвалах угольных разрезов Кузбасса можно рассматривать как ресурсную базу для получения эфирных масел с целью их использования в фармацевтической, химической и других отраслях промышленности.

\section{Список литературы}

1. Баранник Л.П., Николайченко В.П. Лесная фитомелиорация техногенных земель в Кузбассе // Вестник Кузбасского технического университета. 2007. № 5. С. 101-102. 
2. Уфимцев В.И. Формирование надземной фитомассы лесных культур сосны обыкновенной (Pinus sylvestris L.) на породных отвалах в аспекте депонирования углерода атмосферы // Вестник Красноярского государственного аграрного университета. 2013. № 2. С. 68-71.

3. Пентегова Н.М., Дубовенко Ж.В., Ралдугин В.А., Шмидт Э.П. Терпеноиды хвойных растений. Новосибирск, 1987. $97 \mathrm{c}$.

4. Bohlmann Jö., I Keeling Ch. Terpenoid biomaterials // The Plant Journal. 2008. Vol. 54. N 4. Pp. 656-669.

5. Devarenne T.P. Terpenoids: Higher // Encyclopedia of Life Sciences (ELS). John Wiley \& Sons, Ltd: Chichester, 2009 (DOI: 10.1002/9780470015902.a0001916.pub2).

6. Russo E.B. Taming THC: potentialcannabis synergy and phytocannabinoid-terpenoidentourage effects // British Journal of Pharmacology. 2011. Vol. 163. Pp.1344-1364.

7. Neverova O.A., Tsandekova O.L., Domrachev D.V. Study of the composition of ether oils from pine needles of Pinus sylvestris L. growing in various edaphic conditions of Kuzbass surface coal mints dumps // Global Journal of Pharmacology. 2014. Vol. 8. N 3. Pp. 415-419.

8. Egorova I.N., Neverova O.A. Analysis of distribution of radionuclides in various organs of Taraxacum officinale Web., which grows in rock waste disposal areas of coal pits in Kuznetsk basin // World Applied Sciences Journal. 2013. Vol. 24. N 3. Pp. 345-349.

9. Neverova O.A., Egorova I.N. Assessment of heavy metal pollution of medicinal plants Taraxacum officinale Web. growing in the Kuznetsk basin areas affected by coal production // World Applied Sciences Journal. 2013. Vol. 23. N 5. Pp. 650-655.

10. Neverova O.A., Egorova I.N. Assessment of radionuclide pollution of Rosa Majalis herrm fruits in the circumstances of the anthropologically disordered Kuznetsk basin areas // Advances in Environmental Biology. 2014. Vol. 8. N 13. Pp. $414-418$.

11. Ткачев А.В. Исследование летучих веществ растений. Новосибирск, 2008. 969 с.

12. Dormont L., Roques A., Malosse C. Cone and foliage volatiles emitted by Pinus cembra and some related conifer species // Phytochemistry. 1998. Vol. 49. Pp. 1269-1277.

13. De Simon B.F., Vallejo M.C.G., Cadahia E., Miguel C.A., Martinez M.C. Analysis of lipophilic compounds in needles of Pinus pinea L. // Annals of Forest Science. 2001. Vol. 58. Pp. 449-454.

14. Manninen A.M., Tarhanen S., Vuorinen M., Kainulainen P. Comparing the variation of needle and wood terpenoids in Scots pine provenances // Journal of Chemical Ecology. 2002. Vol. 28. Pp. 211-228.

15. Bojovic M. Jurc, D. Drazic, P. Pavlovic, M. Mitrovic, L. Djurdjevic, R.S. Dodd, Z. Afzal-Rafii, M. Barbero. Origin identification of Pinus nigra populations in southwestern Europe using terpene composition variations // Trees: Structure and Function. 2005. Vol. 19. Pp. 531-538.

16. Kupcinskiene E., Stikliene A., Judzentiene A. The essential oil qualitative and quantative composition in the needles of Pinus sylvestris L. growing along industrial transects // Environmental Pollution. 2008. Vol. 155. N 3. Pp. 481-491.

17. Чекушкина Н.В., Невзорова Т.В., Ефремов А.А. Фракционный состав эфирного масла сосны обыкновенной // Химия растительного сырья. 2008. № 2. С. 87-90.

18. Чернодубов А. И., Дерюжкин Р. И. Эфирные масла сосны: состав, получение, использование. Воронеж, 1990. $110 \mathrm{c}$.

19. Kainulainen P., Holopainen J.K. Concentrations of secondary compounds in Scots pine needles at different stages of decomposition // Soil Biology and Biochemistry. 2002. Vol. 34. N 1. Pp. 37-42.

20. Пляшечник М.А. Химический состав эфирного масла Ledum palustre L. (Ericaceae) при увеличении содержания доступного азота в почве криолитозоны (Центральная Эвенкия) // Химия растительного сырья. 2012. № 2. С. 139-144.

21. Фуксман И.Л. Влияние природных и антропогенных факторов на метаболизм веществ вторичного происхождения у древесных растений. Петрозаводск, 2002. 164 с.

22. Сотникова О.В., Степень Р.А. Эфирные масла сосны как индикатор загрязнения среды // Химия растительного сырья. 2001. № 1. С. 79-84.

Поступило в редакциию 29 октября 2016 г.

После переработки 23 ноября 2016 г. 
Neverova O.A. ${ }^{I}$, Tsandekova O.L. ${ }^{2}{ }^{*}$ RESEARCH TERPENE FRACTION OF ESSENTIAL OIL OF NEEDLES OF SCOTS PINE (PINUS SYLVESTRIS L.), GROWING UNDER WASTE DUMP KEDROVSKY COAL CUT

${ }^{I}$ Kemerovo State University, ul. Krasnaya, 6, Kemerovo, 650043 (Russia), e-mail: nev11@yandex.ru

${ }^{2}$ Institute of human ecology of the Federal research center of coal and coal chemistry, Siberian branch of the Russian

Academy of Sciences, pr. Leningradsky, 10, Kemerovo, 650065 (Russia), e-mail: zandekova@bk.ru

The method of gas chromatography-mass spectrometry studied qualitative and quantitative composition of the terpene fractions of essential oils derived from the needles of Pinus sylvestris L., growing in terms of waste dump Kedrovsky coal cut in Kuzbass. The research results were recorded on a Agilent 5973N and Agilent 5973N EI / PCI. Separation of the components of essential oils was performed on a gas chromatograph Agilent 6890 series, members of the chromatography-mass spectrometry systems. Mass spectra were recorded on a quadrupole mass spectrometer HP MSD 5971 with electron impact ionization with energy ionizing elektronov $70 \mathrm{eV}$. Studies iidentifitsirovano 37 components terpene fractions of essential oils, including 14 - and 23 monoterpenes - sesquiterpenes. The influence of edaphic conditions Embryozems blade and age composition of conifer trees on P. sylvestris terpenes. Deficiency in Embryozems nitrate nitrogen and mobile phosphorus contributed to the increase in the total content of terpenes from trees of different ages. Increase of the amount of terpenes in the second class of plant age compared with younger trees. The results of the research give reason to consider Scots pine plantations on dumps of Kuzbass coal mines, as a resource base for essential oils.

Keywords: Pinus sylvestris L., essential oils, terpenes, monoterpenes, sesquiterpenes, dumps coal cut.

\section{References}

1. Barannik L.P., Nikolaichenko V.P. Vestnik Kuzbasskogo tekhnicheskogo universiteta, 2007, no. 5, pp. 101-102. (in Russ.).

2. Ufimtsev V.I. Vestnik Krasnoiarskogo gosudarstvennogo agrarnogo universiteta, 2013, no. 2, pp. 68-71. (in Russ.).

3. Pentegova N.M., Dubovenko Zh.V., Raldugin V.A., Shmidt E.P. Terpenoidy khvoinykh rastenii. [Terpenoids of conifers]. Novosibirsk, 1987, 97 p. (in Russ.).

4. Bohlmann Jö., I Keeling Ch. The Plant Journal, 2008, vol. 54, no. 4, pp. 656-669.

5. Devarenne T.P. Encyclopedia of Life Sciences (ELS), John Wiley \& Sons, Ltd: Chichester, 2009 (DOI: 10.1002/9780470015902.a0001916.pub2).

6. Russo E.B. British Journal of Pharmacology, 2011, vol. 163, pp.1344-1364.

7. Neverova O.A., Tsandekova O.L., Domrachev D.V. Global Journal of Pharmacology, 2014, vol. 8, no. 3, pp. 415-419.

8. Egorova I.N., Neverova O.A. World Applied Sciences Journal, 2013, vol. 24, no. 3, pp. 345-349.

9. Neverova O.A., Egorova I.N. World Applied Sciences Journal, 2013, vol. 23, no. 5, pp. 650-655.

10. Neverova O.A., Egorova I.N. Advances in Environmental Biology, 2014, vol. 8, no. 13, pp. 414-418.

11. Tkachev A.V. Issledovanie letuchikh veshchestv rastenii. [Research of volatile substances of plants]. Novosibirsk, 2008, 969 p. (in Russ.).

12. Dormont L., Roques A., Malosse C. Phytochemistry, 1998, vol. 49, pp. 1269-1277.

13. De Simon B.F., Vallejo M.C.G., Cadahia E., Miguel C.A., Martinez M.C. Annals of Forest Science, 2001, vol. 58, pp. 449-454.

14. Manninen A.M., Tarhanen S., Vuorinen M., Kainulainen P. Journal of Chemical Ecology, 2002, vol. 28, pp. 211-228.

15. Bojovic M. Jurc, D. Drazic, P. Pavlovic, M. Mitrovic, L. Djurdjevic, R.S. Dodd, Z. Afzal-Rafii, M. Barbero. Trees: Structure and Function, 2005, vol. 19, pp. 531-538.

16. Kupcinskiene E., Stikliene A., Judzentiene A. Environmental Pollution, 2008, vol. 155, no. 3, pp. 481-491.

17. Chekushkina N.V., Nevzorova T.V., Efremov A.A. Khimiia rastitel'nogo syr'ia, 2008, no. 2, pp. 87-90. (in Russ.).

18. Chernodubov A. I., Deriuzhkin R. I. Efirnye masla sosny: sostav, poluchenie, ispol'zovanie. [Essential oils of pine: composition, production, use]. Voronezh, 1990, 110 p. (in Russ.).

19. Kainulainen P., Holopainen J.K. Soil Biology and Biochemistry, 2002, vol. 34, no. 1, pp. 37-42.

20. Pliashechnik M.A. Khimiia rastitel'nogo syr'ia, 2012, no. 2, pp. 139-144. (in Russ.).

21. Fuksman I.L. Vliianie prirodnykh $i$ antropogennykh faktorov na metabolizm veshchestv vtorichnogo proiskhozhdeniia $u$ drevesnykh rastenii. [The influence of natural and anthropogenic factors on the metabolism of substances of secondary origin in woody plants]. Petrozavodsk, 2002, 164 p. (in Russ.).

22. Sotnikova O.V., Stepen' R.A. Khimiia rastitel'nogo syr'ia, 2001, no. 1, pp. 79-84. (in Russ.).

Received October 29, 2016

Revised November 23, 2016

\footnotetext{
* Corresponding author.
} 